\title{
Observer effects in a remote population of large-headed capuchins, Sapajus macrocephalus
}

\section{Chloë Alexia Metcalfe ${ }^{1}$ D $\cdot$ Alfredo Yhuaraqui Yaicurima ${ }^{2} \cdot$ Sarah Papworth $^{1}$}

Received: 17 February 2021 / Accepted: 9 October 2021 / Published online: 6 December 2021

(c) The Author(s) 2021

\begin{abstract}
Human observers often are present when researchers record animal behavior, which can create observer effects. These effects are rarely explicitly investigated, often due to the assumption that the study animal is habituated to or unaffected by a human's presence. We investigated the effect of human pressure gradients on a remote population of large-headed capuchins, Sapajus macrocephalus, looking specifically at the effects of number of observers, distance to observers, and distance to the research base. We conducted this study over 4 months in the Pacaya-Samiria Nature Reserve, Peru, and collected 199 two-minute focal samples of capuchin behavior. We found that capuchin monkeys fed less when human observers were closer to the focal individual, when more observers were present, and when capuchins were closer to the research base. We found no other consistent differences in capuchin monkey behavior across the measured human pressure gradients, although capuchins directed a high proportion of their vigilance toward humans (29\% in adults and $47 \%$ in infants). Our results support the hypothesis that human pressure gradients influence animal behavior. Given the proportion of human directed vigilance, we recommend that all studies that use human observers to record animal behavior consider human-directed vigilance, record the number of observers, as well as the observer-focal animal distance, to check for these effects.
\end{abstract}

Keywords Animal behavior · Human influence · Vigilance · Peruvian Amazon

Chloë Alexia Metcalfe

chloe.metcalfe.2012@live.rhul.ac.uk

1 Royal Holloway University of London, Surrey, UK

2 FundAmazonia, Iquitos, Peru 


\section{Introduction}

Observer effects occur when the behavior of studied organisms changes in response to researcher presence (McDougall, 2012). Some researchers mitigate these changes by habituating study animals before data collection takes place (Crofoot et al., 2010; Williamson \& Feistner, 2011). However, even if study animals are habituated, some behaviors, such as vigilance, can change over a behavioral study (Jack et al., 2008). For example, habituated groups of white-faced capuchins, Cebus capucinus, increase their observer-directed behavior, including vigilance and alarm calls, and become more agitated when exposed repeatedly to humans, whereas nonhabituated groups show fewer displays of agitation as behavioral studies progress (Jack et al., 2008). Samango monkeys, Cercopithecus mitis erythrarcus, decrease their vigilance and eat more food from ground-level feeding sites in the presence of humans, suggesting that they perceive less threat from terrestrial predators when humans are present (Nowak et al., 2014; Nowak et al., 2016). In habituated groups, different individuals have different tolerances to human presence and therefore different flight initiation distances (Allan et al., 2020). These examples show how human presence can change animal risk perception and animal behavior. These effects could mean that deductions from research using human observers to collect data may not hold true for individuals that are less exposed to humans, for example, in very remote populations.

We can test for observer effects in the presence and absence of humans. For example, wild white-faced capuchins, Cebus capucinus, which researchers had fitted with remote sensors on radio collars to collect movement and location data, showed that spatial capuchin behavior did not change in the presence of humans (Crofoot et al., 2010). However, understanding observer effects requires information on other behaviors (such as feeding and vigilance) that researchers cannot so easily measure remotely. One alternative method to understand how observers can affect behavior is to explore how animal behavior changes with changes in human presence gradients. Previous research has used the term "human pressure gradient" to investigate spatiotemporal changes in land-use along a gradient of population density (Biasi et al., 2017); we extend the term to include any spatial or temporal changes in diverse measures of human encounters with animals, for example, the frequency of encounters, number of observers, or distances between observers and animals.

Previous studies that have looked at observer effects with differing human pressure gradients have found evidence of behavioral change across a range of taxa (Baker \& McGuffin, 2007; LaBarge et al., 2020; Pereira et al., 2016). Fur seals, Arctocephalus australis, usually react to human approaches of less than $10 \mathrm{~m}$ by moving away, although sometimes they threaten the observer by orienting their head toward them (Cassini, 2001). As many animals move away with decreasing human distance, researchers have used flight initiation distance as a proxy for fearfulness across species (Stankowich \& Blumstein, 2005). Animals also change their behavior in areas and at times when they encounter more humans (Geffroy et al., 2015; Mikula et al., 2018; Riley et al., 2016). Brown bears, Ursus arctos, 
make beds in areas of denser foliage during the day (when human activity is greater) than they do at night, and rest further from towns and villages during the hunting season (Ordiz et al., 2011). A review of the effects of tourists on animal behavior showed various species exhibit greater behavioral change when more tourists are present (Geffroy et al., 2017).

Researchers have assumed that animals change their behavior as they are disturbed by increasing human pressure gradients. For example, animals scratch more after stressful events (Palagi and Norscia, 2011). Thus, as Barbary macaques, Macaca sylvana, scratch more when there are larger groups of human observers (Maréchal et al., 2011), this suggests that they find larger groups of human observers stressful. Wild animals also feed less when humans are closer (Parsons et al., 2016) and increase their vigilance when repeatedly exposed to humans (Jack et al., 2008). Nevertheless, although we have some understanding of how human pressure gradients affect animal behavior, there is still more that can be learnt, particularly for poorly studied animals in remote locations.

Animal behavior is affected by many variables in addition to human pressure gradients. For example, denser habitats provide more opportunities for terrestrial predators to hide and, thus, increase prey vigilance (Coleman \& Hill, 2014; Makin et al., 2012), and higher numbers of fruiting trees can increase competition between primates, also causing increases in vigilance (Stevenson et al., 2000).

We investigated the effect of human pressure gradients and habitat on animal behavior in a remote population of primates. Using large-headed capuchins, Sapajus macrocephalus, as a study species, we also address the lack of behavioral studies on wild Amazonian Sapajus species (Lynch Alfaro et al., 2014) and provide information on the possible impact of observer effects in future studies. Primates are quick to adapt to new situations (Jack et al., 2008; Kalbitzer \& Chapman, 2018), so they are anticipated to adapt to varying levels of human pressure gradients at a scale that can be investigated in a short-term behavioral study.

The purpose of this study is to determine whether human pressure gradients and habitat affect the behavior of a remote population of capuchins. We explore behavioral differences with (1) decreasing distance between an observer and their subject; (2) decreasing distance between a research base and the subject; (3) increasing numbers of observers; and (4) habitat variables, including density and number of fruiting tees. If capuchins perceive humans as a threat, we predict that human-directed vigilance, scratching, and time out of view will increase, whereas feeding will decrease, with increasing human pressure gradients. If capuchins perceive dense habitats as high-risk areas from predators and their conspecifics as competitors for food, then we predict that vigilance also will increase as the habitat becomes denser and the number of fruiting trees increases.

\section{Methods}

\section{Study site}

Our research took place in Pacaya Samiria Nature Reserve, Peru, at the remote "Puesto de Vigilancia 2" (PV2) - Tacshacocha. This area has low hunting pressure 
due to its distance from the major town of Nauta and city of Iquitos (Bodmer \& Lozano, 2001). The research base (S0571327, W9460683) has the greatest density of humans in the immediate area, with living quarters for researchers and a park guard hut. Operation Wallacea expeditions conducted primate behavioral studies at the site for a minimum of 6-8 weeks per year from 2010-2018 (Bodmer et al., 2018). For more than 35 years, researchers have repeatedly visited the larger region of the research site to collect data on wildlife and environmental variables (Puertas et al., 1995; Bodmer et al., 2009; Bodmer et al., 2018). However, the capuchins at PV2 are only occasionally exposed to humans, as there is little human pressure and no hunting.

Large-headed capuchins are medium sized primates with a semi-prehensile tail that live at high densities in a range of forest habitats (Lynch Alfaro et al., 2012). They have a black cap on their forehead that researchers can use to identify individuals due to its distinctive form, together with other facial markings (Pokorny \& Waal, 2009). There are aerial and terrestrial predators of capuchins in the reserve, with a diversity of raptors (Knight, 2010), the jaguar (Panthera onca), ocelot (Leopardus pardalis), and puma (Puma concolor) (Pittet \& Bennett, 2014) present.

We conducted this study from 22 April to 3 August 2018. Data collection occurred daily from 07.00-12.00 and 14.00-17.30. We paused data collection at midday for scheduled lunch breaks for research assistants - a feature of this field site. For the purpose of this study, we used ten transects of approximately 3-km each, established near the research base in 2010 for long-term monitoring of many taxa (Bodmer et al. 2018). The distance between transects varies. We were unable to sample all transects equally due to external circumstances, such as temporary flooding of some transects (Bodmer et al. 2018). Furthermore, the primary goals of the long-term research project at this site took precedence over the needs of this study. Therefore, we could only use transects when sampling was not taking place for the long-term research project (Fund Amazonia, 2021). We did not sample transects in the afternoon that had been visited by other researchers in the morning, because many of the protocols (e.g., for habitat sampling) for the long-term project did not restrict noise and included placement of research materials, such as mist nets and cameras traps.

Within these constraints, we chose one of ten transects at random for morning data collection and a different transect for afternoon data collection. We walked the transect until we found a group of large-headed capuchins. We randomly selected one of the visible individuals in this group as the subject of a 2-minute focal sample (Altmann, 1974), and we recorded the behavior and habitat variables detailed below.

We recorded the age class of the individual as infant, juvenile, subadult, or adult-identifiable by body size and proportions. The characteristics that we used to distinguish between age class included:

- Infants - small body size and carried by others with no independent locomotion;

- Juveniles - smaller than adults and larger heads relative to body size with fuzzier pelage; can move around by themselves but less confident in their locomotion than adults; 
- Subadults — not fully grown but resembled adults in pelage and locomotor ability;

- Adults-fully grown individuals that were sexually mature.

Where possible, we also recorded the group and individual identity (using facial characteristics and group composition to identify groups). When we could not identify a group, it was assigned a unique identification number. Once we had recorded data on this individual, another visible individual in the group was chosen at random and another focal sample was taken. We repeated this until all individuals in the group had been used for the data collection or until we could no longer follow the group. To prevent pseudo-replication, if we could not identify an individual that was distinct from the previous samples for that day, we left the primate group and we began searching for a new group. We recorded the location of groups, and if we recognised the group or it was likely to be the same group already sampled on that day (based on group structure, individual facial features, and the time and location of the previous sighting), then we would not sample the group again. We only recorded multiple capuchin groups on the same transect on the same day 19 times. We located three groups on the same transect on only 3 days, whereas the other 16 cases featured only two groups, demonstrating the low likelihood of unknowingly sampling the same group twice in a day.

\section{Measuring behavior}

One observer recorded all behavioral data by observing the focal individual through binoculars (vector $8 \times 42$ waterproof binoculars) during a 2-minute focal sample and described the behaviors observed. A second observer entered the data into "Behavioral Observation Research Interactive Software" (BORIS) (Friard \& Gamba, 2016), installed on a Lenovo HLA2-U8P(10) tablet. There was always a minimum of two observers to comply with field safety regulations (range 2-6). BORIS recorded the duration of the behavioral states feeding, locomotion, resting, and when the focal individual was out of view in seconds using time stamps (Table I). We also recorded scratching and vigilance (Table I) as point event behaviors.

\section{Human influence}

We measured the distance between the base and the location of the individual at the end of the focal sample (measured using an etrex 10 Garmin GPS) in metres. We recorded the number of people present during data collection and horizontal distance between the observer and the focal individual at the end of the 2-minute sample, which varied from 1-60 m. We measured the distance using a Silverline MT40 50 m fiberglass surveyors tape or a Track life 60-m laser distance meter. 


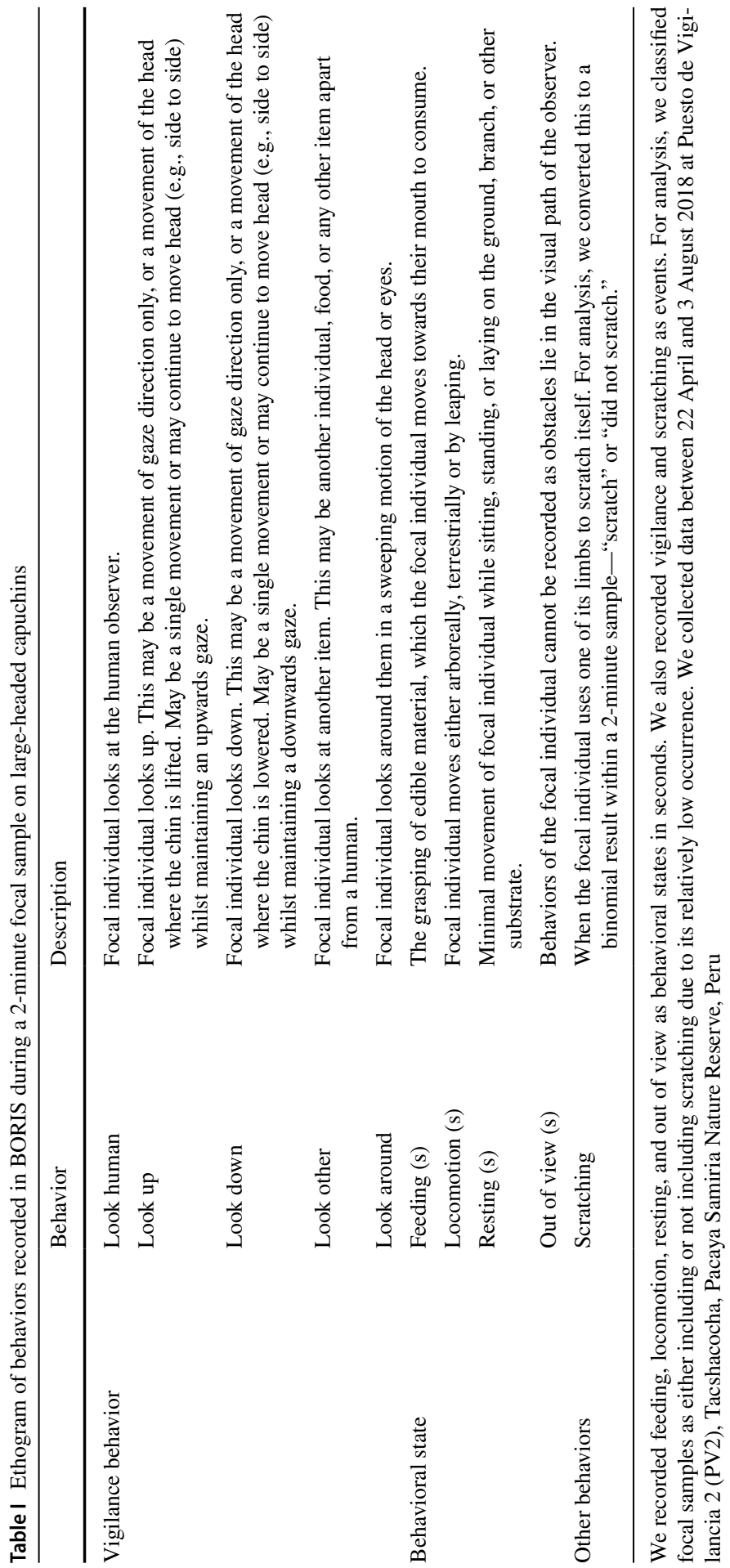




\section{Measuring habitat}

We also recorded variables that can impact behavior, including habitat characteristics, group size, and age class (infant, juvenile, subadult or adult, identifiable by body size and proportions) of the focal individuals. We measured three habitat variables at the location of an individual at the end of the 2-minute focal sample: type of habitat (liana, levee, or other), and the number of fruiting trees and tree crowns within $5 \mathrm{~m}$ (Table II). We also calculated the height of the focal individual using the distance from the observer to immediately below the location of the individual (using a Silverline MT40 50-m fiberglass surveyors tape or a Track life 60-m laser distance meter), the angle of observation (measured with a BM5/360PC Suunto $360^{\circ}$ clinometer), and the eye height of the observer.

\section{Statistical analysis}

We used five response variables to measure capuchin behavior: counts of humandirected vigilance and nonhuman vigilance (all other vigilance); number of seconds spent feeding; whether we observed scratching behavior during a focal sample; and the number of seconds the capuchin was out of view. We included capuchin age class (infant, juvenile, subadult, adult), number of nearest neighbours (number of individuals within $5 \mathrm{~m}$ of the focal individual), the number of human observers, the distance to the observer, the distance to the base, the height of the capuchin, the total crowns, habitat type (levee, liana, or other), and the number of fruiting trees as explanatory variables in all analyses. We used multiple generalised linear mixed models (GLMM) in RStudio version 1.1.442, R version 3.4.4 ( $\mathrm{R}$ Core Team, 2018), with the monkey group $(\mathrm{N}=48)$ included as a random effect and an interaction term between the number of observers and the distance to the base camp in all models. We used diagnostic plots of the predictions and residuals to check the assumptions of all models. We conducted type II ANOVAs on human directed vigilance, feeding and scratching GLMMs to test the significance of the explanatory variables, and type III ANOVAs on the nonhuman vigilance and out of view GLMMs due to the significance of the interaction. The human directed vigilance model uses a zero inflated error structure within the R package GLMM Template Model Builder (glmmTMB) (Broüoks et al., 2017), and we calculated $\mathrm{R}^{2}$ using the sjstats package (Lüdecke, 2019). We use the optimizer bobyqa to undertake the nonhuman vigilance and the feeding GLMMs and the r.squaredGLMM function from the MuMIn package (Barton, 2018) to calculate $\mathrm{R}^{2}$. We report the trigamma estimate for both the marginal and conditional $\mathrm{R}^{2}$ values for all models with numerical response variables. As we analysed the time out of view, feeding and scratching models with a binomial distribution, we report the theoretical marginal and conditional $\mathrm{R}^{2}$. The feeding model compares the time the capuchin was in view and feeding, with when they were in view and not feeding. We conducted post-hoc Tukey tests using the ghlt function in the multcomp package (Hothorn et al., 2008) for all GLMMs except the zero inflated 


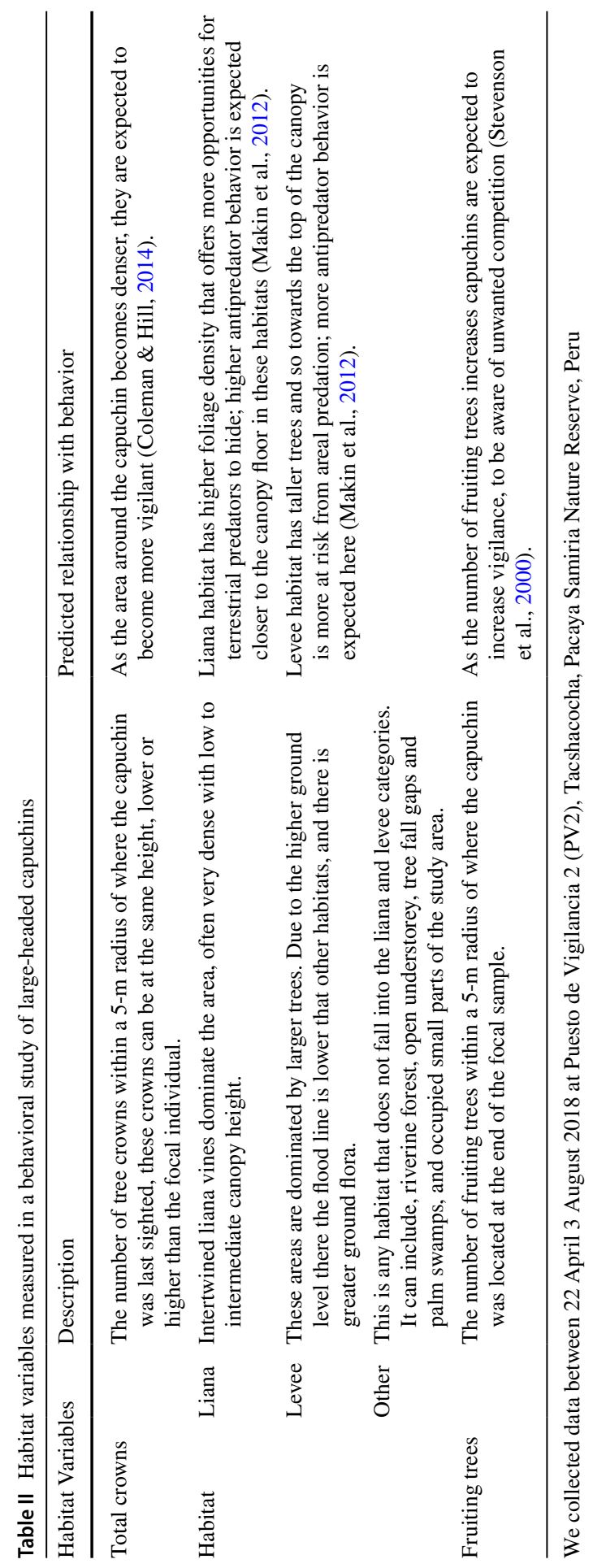


human vigilance model where we used the emmeans package (Lenth, 2019). All these analyses used an alpha level of 0.05 .

We made 199 observations of individuals, but the number of individuals included in analyses (N) varies 138-167 due to NAs. For all statistical analyses, we filtered the dataset to remove groups where we only sampled one capuchin, as uneven sampling of random effects can result in unstable model estimates (Harrison et al., 2018). We encountered a maximum of 92 capuchin groups on the 10 transects. For the models of nonhuman vigilance, human vigilance, feeding, and scratching behavior, these 199 observations only included capuchins that had been in view for at least 70 seconds in a 2-minute focal sample $(n=167)$.

\section{Ethical note}

The Royal Holloway University of London University Research Ethics committee approved the research prior to its commencement. We followed all applicable institutional and/or national guidelines for the care and use of animals.

Data availability The datasets generated during the current study are not publicly available but are available from the corresponding author on reasonable request.

\section{Results}

Large-headed capuchins looked at an observer 1.6 \pm SD $2.3(\mathrm{~N}=199)$ times in a 2-minute focal sample and made a mean of $2.9 \pm$ SD 2.9 nonhuman vigilance scans $(\mathrm{N}=199)$. Capuchins displayed more human-directed vigilance in liana habitats, and focal individuals showed highest human directed vigilance when they were closer to the ground (Fig. 1). No other independent variables had a significant effect on human directed vigilance by capuchin monkeys (Table III). The fixed effects explain $43 \%$ of the variance in human-directed vigilance (Poisson GLMM, marginal $\mathrm{R}^{2}=0.43$, conditional $\mathrm{R}^{2}=0.52, \mathrm{~N}=139$ ).

Capuchins displayed more non-human vigilance in levee and liana habitats than in "other" habitats (Table III), but all Tukey post hoc tests were nonsignificant. Nonhuman vigilance was not significantly affected by any other measured independent variable (Table III). The fixed effects explain $30 \%$ of the variance in nonhuman vigilance (Poisson GLMM, marginal R2 $=0.30$, conditional R2 $=0.52, \mathrm{~N}=167$ ).

Capuchins spent a mean of $41 \pm$ SD 41 seconds of a 2 minute focal sample (N $=199$ ) feeding. Individuals fed less when more observers were present (Table III; Fig. 2), although a Tukey post hoc test was nonsignificant. Capuchins increased feeding as the distance to the observer increased (Fig. 2), in larger groups, in habitats with more crowns within $5 \mathrm{~m}$, when further from the research base, and when closer to the ground (Table III). Capuchins also fed more in levee than in liana habitat (Table III, post-hoc Tukey test, levee-liana $\mathrm{Z}=3.54, \mathrm{P}=0.001$ ). Capuchin feeding behavior was not associated with differences in the number of 


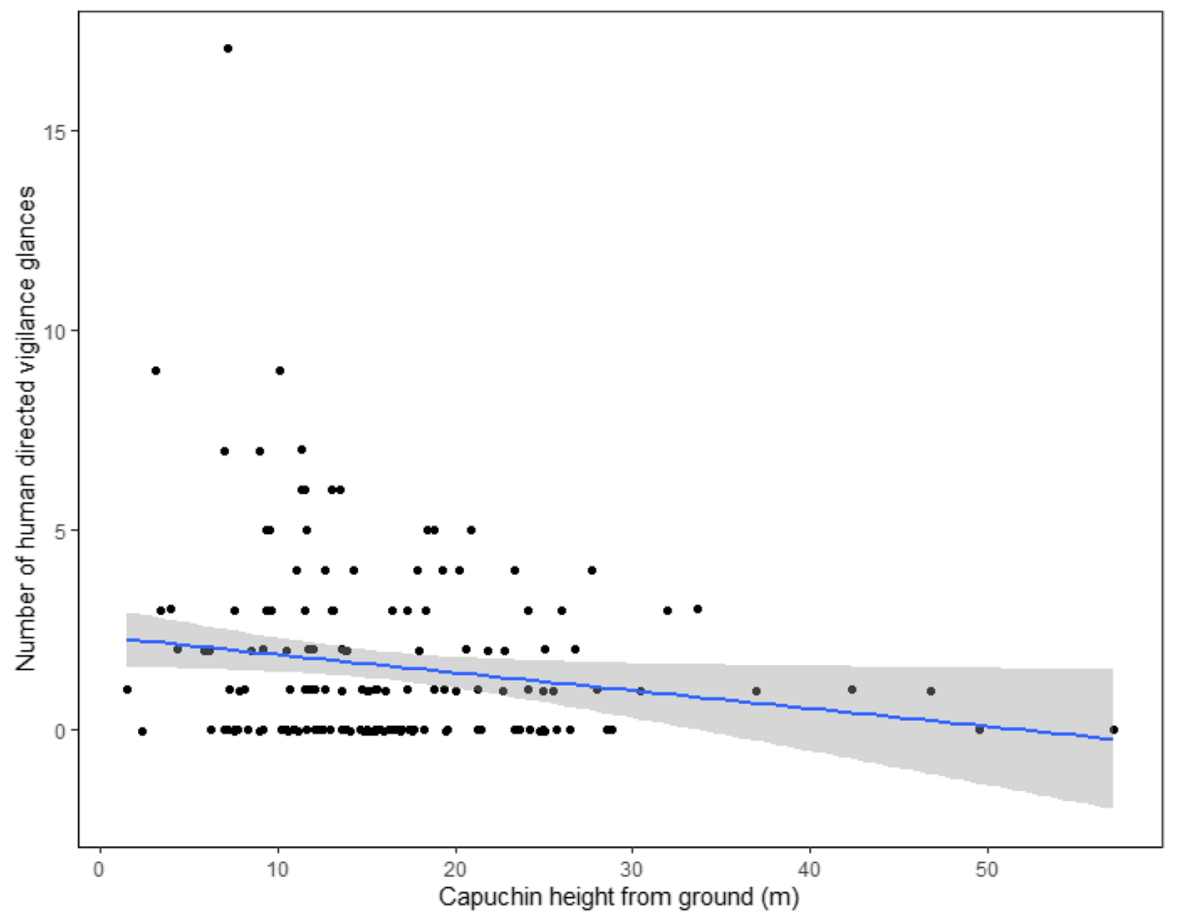

Fig. 1 The frequency that large-headed capuchins showed human directed vigilance during a 2-minute focal sample vs. the height of the capuchin. We used the function geom_smooth() with method glm to draw the prediction and standard error from the model. We added a $0.02-\mathrm{cm}$ jitter to allow overlapping points to be viewed. We collected data between 22 April and 3 August 2018 at Puesto de Vigilancia 2 (PV2), Tacshacocha, Pacaya Samiria Nature Reserve, Peru.

fruiting trees (Table III). The fixed effects explain $21 \%$ of this model (Binomial GLMM, marginal $\mathrm{R}^{2}=0.21$, conditional $\left.\mathrm{R}^{2}=0.99, \mathrm{~N}=139\right)$.

Capuchins scratched in $57 \%$ of focal observations $(\mathrm{N}=199)$. The model explained $16 \%$ of the variance during the observations (Binomial GLMM, marginal $\mathrm{R}^{2}=0.16$, conditional $\mathrm{R}^{2}=0.16, \mathrm{~N}=138$ ), but this was due to group level differences in scratching and none of the fixed effects were significantly associated with scratching (Table III).

The capuchins were out of view for a mean of $15 \mathrm{~s} \pm \mathrm{SD} 21(\mathrm{~N}=199)$ in a 2-minute sample. The number of observers had a significant effect on the time the capuchin spent out of view (Table III). A post-hoc Tukey showed the difference lay between two and three observers $(Z=3.59, P=0.002)$ and three and four $(Z$ $=-3.40, \mathrm{P}=0.004)$. The higher the capuchin, and the fewer crowns within $5 \mathrm{~m}$, the more time they spent out of view (Table III). Capuchins also spent more time out of view in the liana habitat than levee or other habitats (Table III, post-hoc Tukey, liana - levee $\mathrm{Z}=3.93, \mathrm{P}<0.001$; liana - "other" $\mathrm{Z}=3.62, \mathrm{P}<0.001$ ). None of the other fixed effects were significantly associated with the time spent out of view (Table III). Overall, the fixed effects in the model explained $43 \%$ of 


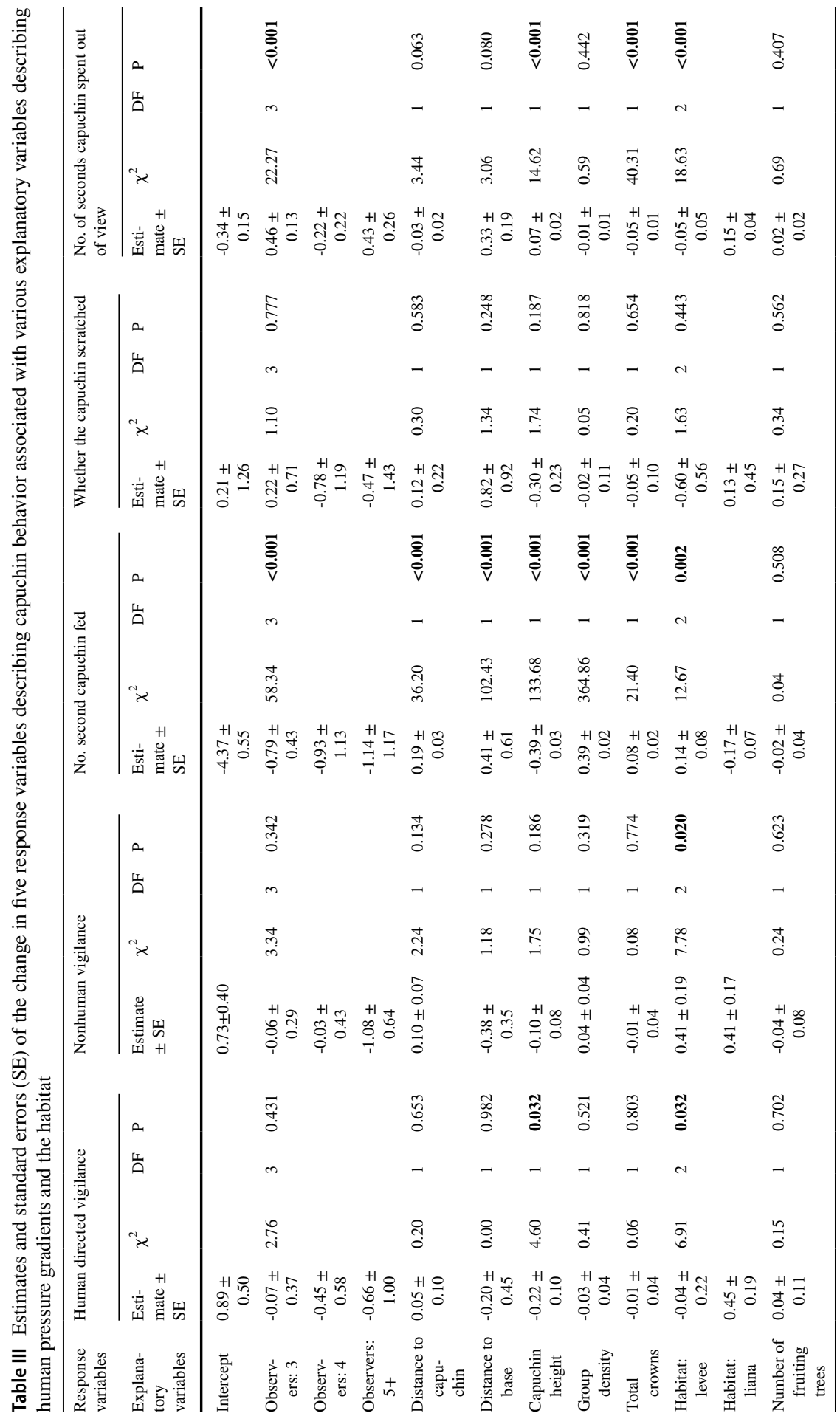




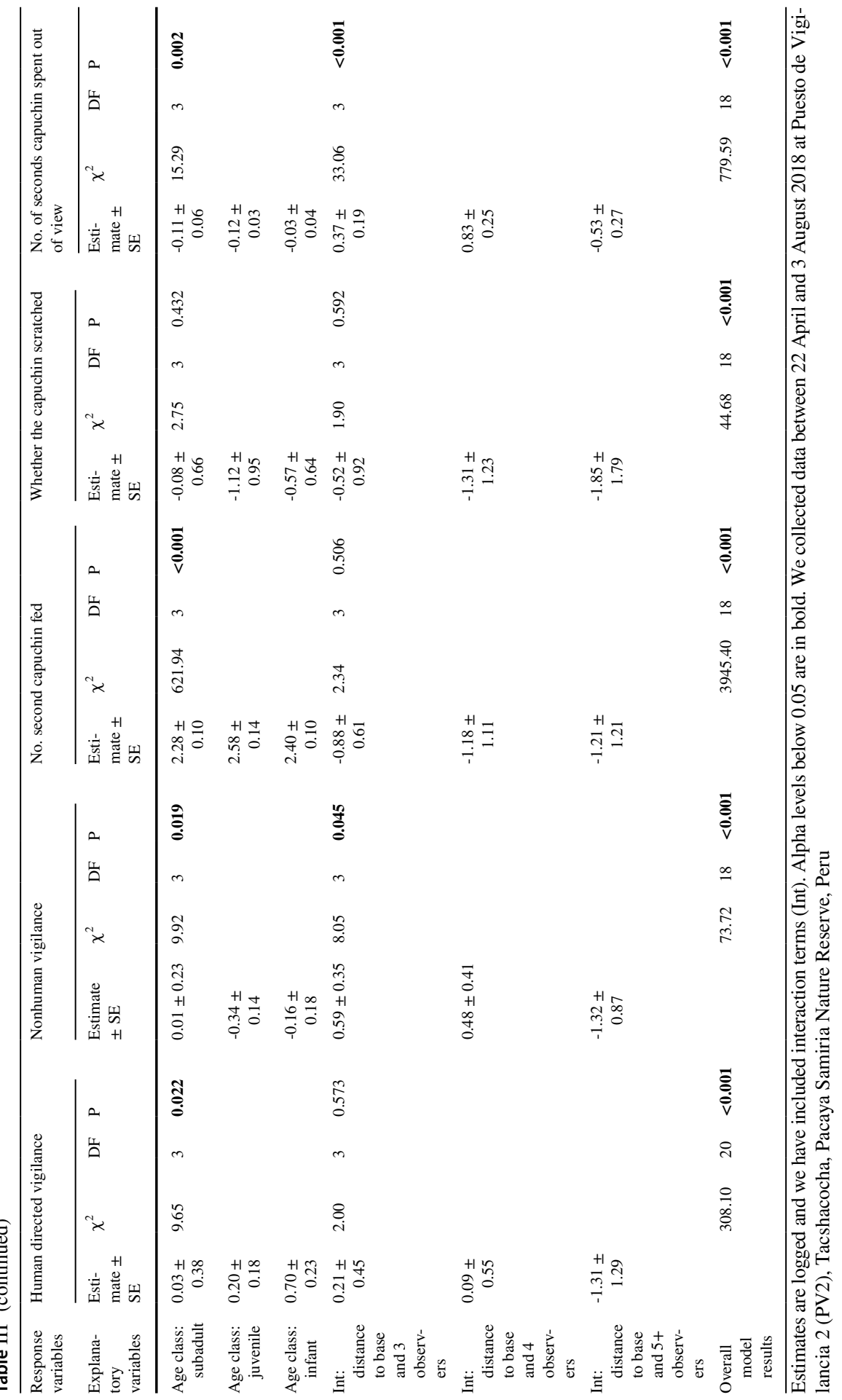




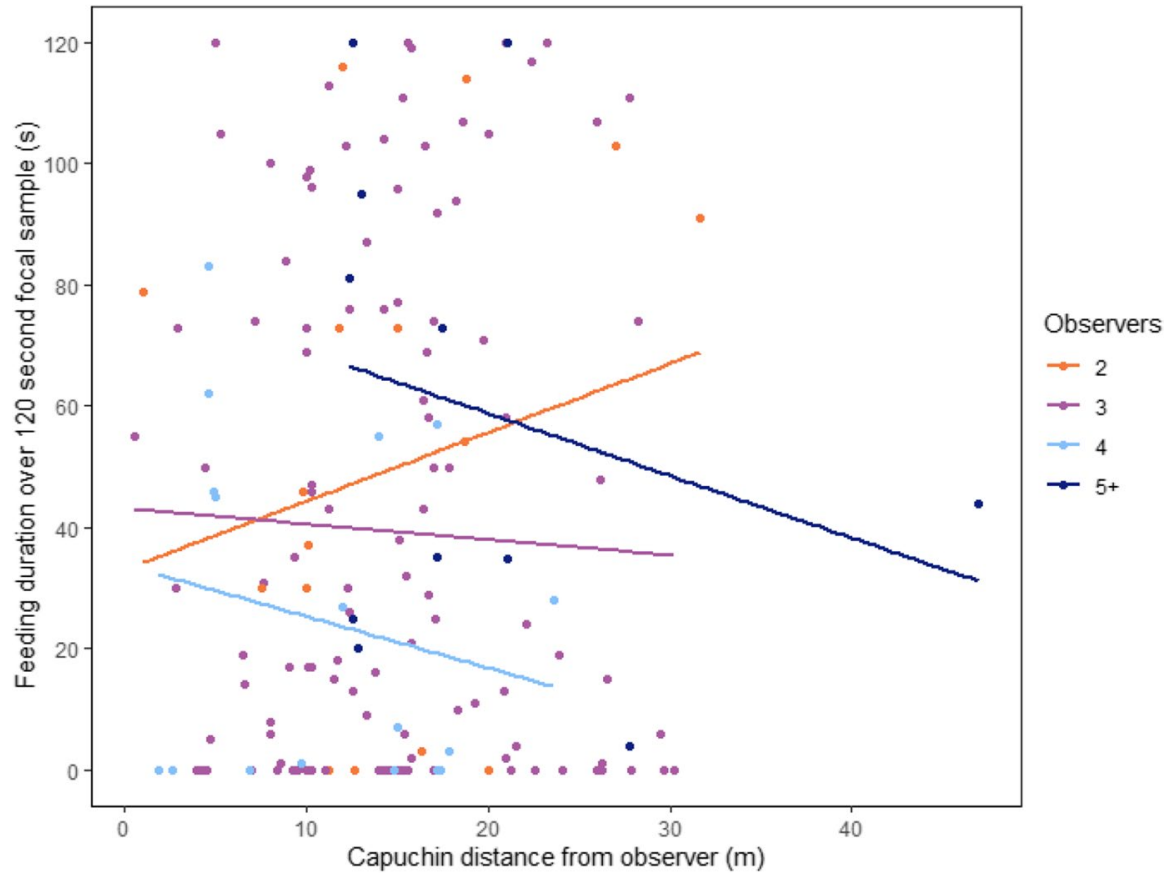

Fig. 2 Focal individual feeding behavior plotted against the distance from large-headed capuchins to the observers (measured in seconds over a 2-minute focal sample). We added a $0.02-\mathrm{cm}$ jitter to allow overlapping points to be viewed. We collected data between 22 April and 3 August 2018 at Puesto de Vigilancia 2 (PV2), Tacshacocha, Pacaya Samiria Nature Reserve, Peru.

the variation in the number of seconds a focal capuchin was out of view (Binomial GLMM, marginal R2 $=0.43$, conditional R2 $=0.96, \mathrm{~N}=165$ ).

\section{Discussion}

We found that human pressure gradients are associated with behavioral changes in large-headed capuchins, in a remote location in the Pacaya-Samiria Nature Reserve, Peru. First, capuchins spent more time feeding when fewer observers were present, and when they were further away from the observers and research base. This supports the hypothesis that capuchins perceive an increase in human pressure as a threat (Makin et al., 2012; Nowak et al., 2016). Reduced feeding in areas of high perceived threat is an antipredator strategy: vervet monkeys, Chlorocebus aethiops, reduce feeding at the base of trees and the tops of the canopy in response terrestrial and aerial predation, respectively (Makin et al., 2012), and samango monkeys, Cercopithecus albogularis schwarzi, reduce feeding when exposed repeatedly to live trapping (Nowak et al., 2016). Other taxa show similar responses: white tailed deer, Odocoileus virginianus, eastern grey squirrel, Sciurus carolinensis, and northern raccoon, Procyon lotor, perceive humans as a greater threat than their natural predator, the coyote, Canis latrans 
- feeding less when humans were closer, and even less so when humans are accompanied by a domestic dog, Canis familiaris (Parsons et al., 2016).

Although we did not find an association between capuchin vigilance and increases in human presence, studied individuals directed a non-trivial proportion of vigilance behavior at humans ( $>25 \%$ on average across all age classes). Future studies could compare vigilance behavior in the presence and absence of observers to understand if individuals are increasing their overall vigilance, or reducing vigilance directed elsewhere. Researchers usually measure vigilance behavior as a single variable (Busia et al., 2016) or separated into antipredator and social vigilance (Hirsch, 2002), but human directed vigilance often is not distinguished or recorded. Due to variability in definitions of vigilance behavior, it is difficult to compare vigilance between primate studies (Allan \& Hill, 2018). As our understanding of predation risk increases, it becomes increasingly important to separate and carefully define different types of vigilance. This is especially true as responses to anthropogenic disturbance stimuli, such as loud noises and objects that approach at a rapid speed, are likened to predation risk (Frid \& Dill, 2002).

Displacement activities, such as scratching, indicate stress (Schino et al., 1991; Troisi, 2002). Increased scratching is associated with larger groups of human observers (Maréchal et al., 2011). Although capuchins did not show changes in scratching with the human pressure gradients measured in our study, the method of data collection may have influenced this outcome as we did not use scratching duration. Researchers usually record scratching as episodes per hour (Maréchal et al., 2011; Palagi \& Norscia, 2011; Schino et al., 1991) but we used presence and absence of scratching due to the short duration of focal samples.

The amount of time a capuchin was out of view was associated with the number of observers. However, contrary to our predictions, capuchins did not consistently spend more time out of view as the number of observers increased. This result may be due to other factors, which systematically differed between groups with different numbers of human observers but were not measured here. One possibility is that capuchin behavior differs with male and female observers, although we did not record these data. Monkey species, such as the woolly monkey, Lagothrix poeppiggii, can distinguish between hunters, researchers, and forest gathers (Papworth et al., 2013). Because 95\% of hunters are male in Peru (Francesconi et al., 2018), monkeys may perceive male observers as hunters and therefore a threat. Other unmeasured observer variables also may have affected behavior; for example, although observers were as quiet as possible in this study, the noise emitted by the human observers may have differed. Captive orangutans, Pongo pygmaeus, hide more when noise increases (Birke, 2002), and louder conversations reduce visibility of wild pygmy marmosets, Cebuella pygmaea (Sheehan and Papworth, 2019). The behavior and appearance of observers is an area of research that may therefore benefit from further consideration.

\section{Habitat}

Individuals lower in the canopy showed more human directed vigilance, even though we found no relationship between human directed vigilance and horizontal distance to observers. A capuchin monkey $20-\mathrm{m}$ off the ground, but almost directly above a 
human, may be able to correctly assess that the human is less able to approach than if the capuchin is $1-\mathrm{m}$ off the ground but $20-\mathrm{m}$ away, although the actual distance between them is identical. This suggests that capuchins, and possibly other arboreal animals, may use a vertical axis of fear to assess the risk posed by humans (Makin et al., 2012; Nowak et al,. 2014). We expected nonhuman vigilance to change with the habitat, as is the case in other capuchin species (Campos \& Fedigan, 2014), and as we predicted, it was higher in both liana and levee habitats.

In addition to changing behavior, using human observers can bias data collection. Because humans are restricted to the ground, their view of study animals is more likely to be obscured when the focal individual is higher in the canopy and when foliage is denser. This is supported by our results, as capuchins were out of view for longer when they were higher in the canopy and when there were more tree crowns within $5 \mathrm{~m}$. Studies have tried to overcome this, using methods, such as radio collars (Crofoot et al., 2010) and accelerometers (Sellers \& Crompton, 2004), but behaviors, such as vigilance and feeding cannot be measured using these methods.

Capuchins fed most in levees, which are habitats with a wide variety of flora (Jong, 2001) and thus potential sources of food for this opportunistic omnivore (Addessi, 2008). However, the number of fruiting trees did not affect any of the behaviors measured. This result was unexpected, especially as other platyrrhines, such as the squirrel monkey (Saimiri sciureus), decrease their fruit intake during the dry season when there are fewer fruiting trees (Stone, 2007). Other researchers have used feeding as an indicator of levels of risk (Makin et al., 2012). In this study, individuals fed less when higher in the canopy and more in areas of greater crown density. This could be an example of predator sensitive foraging (White et al., 2003), although we found no relationship between non-human directed vigilance and height or crown density, which would have further supported this hypothesis. Habitat density can influence behavior; the blue monkey, Cercopithecus mitis, increases its vigilance in low foliage density (Gaynor \& Cords, 2012), and bats in Honduras fly in straighter lines to cross clearings surrounded by denser foliage than those bordered by more open foliage (Caras \& Korine, 2009).

\section{Conclusions}

We found evidence that the behavior of large-headed capuchin monkeys at a remote location within Pacaya Samiria Nature Reserve differ with various measures of a human pressure gradient. Feeding behavior and the time that an individual spends out of view were associated with the number of human observers. Feeding behavior increased as the distance between the individual, the research base, and observer increased.

Our findings have implications for the collection of behavioral data by human observers. Although we did not find evidence that human pressure gradients are associated with capuchin monkey human-directed vigilance, we nevertheless recommend that human-directed vigilance is distinguished as a separate category in all future animal behavior studies on vigilance. This is due to the high levels of humandirected vigilance observed in this study. The effects of humans on animal behavior 
are not necessarily predictable across sites or species, but with the growing evidence for observer effects, we suggest such measures should be incorporated in all studies of animal behavior to test for and control these effects. The measures we included in this study (human-directed vigilance, observer-subject distance, and observer group size) are relatively simple to include in any animal behavior study and can control for possible observer effects. If researchers record these variables and human-directed vigilance in all animal behavior studies where humans are present, this would allow them to check for behavioral biases, which might be introduced by human observers.

Supplementary Information The online version contains supplementary material available at https://oi. org/10.1007/s10764-021-00264-w.

Acknowledgments This study could not have been completed without the support from a number of individuals. First, a huge thank you to: Jennifer, Paul, Samuel, Mavi, Penney, Christopher, Bob, Irene, and Kate who supported this project in its entirety. Thank you to FundAmazonia headed by Dr. Bodmer, their Field Guides: Sabino, Samuel, and William, Field Assistant Yanina, Staff Beatrice, Medic Sheyla, and Biologists: Kimberlyn, Tino, Nathaly, and Osnar together with Operation Wallacea headed by Georgina and their Biologists: Emma, Juriko, Tara, Matthew, and students, Luke and Monika, all of whom made data collection safe and enjoyable. We also thank the editors and reviewers for their input into the revisions of this manuscript.

\section{Declarations}

Conflict of Interest The authors declare that they have no conflict of interest.ESM1 (PDF $100 \mathrm{~KB}$ )

Open Access This article is licensed under a Creative Commons Attribution 4.0 International License, which permits use, sharing, adaptation, distribution and reproduction in any medium or format, as long as you give appropriate credit to the original author(s) and the source, provide a link to the Creative Commons licence, and indicate if changes were made. The images or other third party material in this article are included in the article's Creative Commons licence, unless indicated otherwise in a credit line to the material. If material is not included in the article's Creative Commons licence and your intended use is not permitted by statutory regulation or exceeds the permitted use, you will need to obtain permission directly from the copyright holder. To view a copy of this licence, visit http://creativecommons.org/licen ses/by/4.0/.

\section{References}

Addessi, E. (2008). Food variety-seeking in tufted capuchin monkeys (Cebus apella). Physiology and Behavior, 93, 304-309.

Allan, A. T. L., \& Hill, R. A. (2018). What have we been looking at? A call for consistency in studies of primate vigilance. American Journal of Physical Anthropology, 165, 4-22.

Allan, A. T. L., Bailey, A. L., \& Hill, R. A. (2020). Habituation is not neutral or equal: individual differences in tolerance suggest an overlooked personality trait. Sciences. Advances, 6, eaaz0870.

Altmann, J. (1974). Observational study of behavior: sampling methods. Behavior, 49, 227-267.

Baker, R. L., \& McGuffin, M. A. (2007). Technique and observer presence affect reporting of behavior of damselfly larvae. Freshwater science, 26, 145-151.

Barton, K. (2018). MuMIn: Multi-model inference. R package version 1.42.1. https://CRAN.R-project. org/package=MuMIn. Accessed 17 Oct 2019.

Biasi, R., Brunori, E., Ferrara, C., \& Salvati, L. (2017). Towards sustainable rural landscapes? A multivariate analysis of the structure of traditional tree cropping systems along a human pressure gradient in a Mediterranean region. Agroforestry Systems, 91, 1199-1217. 
Birke, L. (2002). Effects of browse, human visitors and noise on the behavior of captive orangutans. Animal Welfare, 11, 189-202.

Bodmer, R. E., \& Lozano, E. P. (2001). Rural Development and Sustainable Wildlife Use in Peru. Conservation Biology, 15, 1163-1170.

Bodmer, R., Puertas, P., \& Fang, T. (2009). Comanaging wildlife in the Amazon and the salvation of the Pacaya-Samiria National Reserve in Peru. In: M. Manfredo, J. Vaske, P. Bodmer, R., Mayor, P., Antunez, M. Chota, K., Fang, T., Puertas, P. Pittet, M., Kirkland, M. Walkey, M., Rios, C., PerezPeña, P., Henderson, P. Bodmer, W., Bicerra, A., Zegarra, J. \& Docherty, E. (2018) Major shifts in Amazon wildlife populations from recent climatic intensification. Conservation Biology, 32, 333-344.

Bodmer, R., Mayor, P., Antunez, M., Chota, K., Fang, F., Puertas, P., Pittet, M., Kirkland, M., Walkey, M., Rios, C., Perez-Peña, P., Henderson, P., Bodmer, W., Bicerra, A., Zegarra, J., \& Docherty, E. (2018) Major shifts in Amazon wildlife populations from recent intensification of floods and drought. Conservation Biology, 32, 333-344.

Broüoks, M. E., Kristensen, K., Van Benthem, K. J., Magnusson, A., Berg, C. W., Nielsen, A., Skaug, H. J., Maechler, M., \& Bolker, B. M. (2017). glmmTMB balances speed and flexibility among packages for zero-inflated generalized linear mixed modeling. The R Journal, 9, 378-400.

Busia, L., Schaffner, C. M., \& Aureli, F. (2016). Watch out or relax: conspecifics affect vigilance in wild spider monkeys (Ateles geoffroy). Behavior, 153, 107-124.

Campos, F. A., \& Fedigan, L. M. (2014). Spatial ecology of perceived predation risk and vigilance behavior in white-faced capuchins. Behavioral Ecology, 25, 477-486.

Caras, T., \& Korine, C. (2009). Effect of vegetation density on the use of trails by bats in a secondary tropical rain forest. Journal of Tropical Ecology, 25, 97-101.

Cassini, M. H. (2001). Behavioral responses of South American fur seals to approach by tourists - a brief report. Applied Animal Behavior Science, 71, 341-346.

Coleman, B. T., \& Hill, R. A. (2014). Living in a landscape of fear: the impact of predation, resource availability and habitat structure on primate range use. Animal Behavior, 88, 165-173.

Crofoot, M. C., Lamber, T. D., Kays, R., \& Wikelski, M. C. (2010). Does watching a monkey change its behavior? Quantifying observer effects in habituated wild primates using automated radiotelemetry. Animal Behavior, 80, 475-480.

Francesconi, W., Bax, B., Bludo-Canto, G., Willcock, S., Cuadros, S., Vanegas, M., Quintero, M., \& Torres-Vitolas, C. A. (2018). Hunters and hunting across indigenous and colonist communities at the forest-agriculture interface: an ethnozoological study from the Peruvian Amazon. Journal of Ethnobiology and Ethnomedicine, 14, 54.

Friard, O., \& Gamba, M. (2016). BORIS: a free, versatile open-source event-logging software for video/ audio coding and live observations. Methods in Ecology and Evolution, 7, 1325-1330.

Frid, A., \& Dill, L. (2002). Human-caused disturbance stimuli as a form of predation risk. Conservation Ecology, 6, 11.

Fund Amazonia. (2021). Research Projects Fund Amazonia. https://fundamazonia.org/?page_id=20. Accessed 6 Sept.

Gaynor, K. M., \& Cords, M. (2012). Antipredator and social monitoring functions of vigilance behavior in blue monkeys. Animal Behavior, 84, 531-537.

Geffroy, B., Samia, D. S. M., Bessa, E., \& Blumstein, D. T. (2015). How nature-based tourism might increase prey vulnerability to predators. Trends in Ecology and Evolution, 30, 755-765.

Geffroy, B., Sadoul, B., \& Ellenberg, U. (2017). Physiological and behavioral consequences of human visitation. In D. Blumstein, D. Samia, \& E. Bessa (Eds.), Ecotourism's promise and peril (pp. 9-27). Springer.

Harrison, X. A., Donaldson, L., Correa-Cano, M. E., Evans, J., Fisher, D. N., Goodwin, C. E. D., Robinson, B. S., Hodgson, D. J., \& Inger, R. (2018). A brief introduction to mixed effects modelling and multi-model inference in ecology. PeerJ, 6, e4794.

Hirsch, B. T. (2002). Social monitoring and vigilance behavior in brown capuchin monkeys (Cebus apella). Behavioral Ecology and Sociobiology, 52, 458-464.

Hothorn, T., Bretz, F., \& Westfall, P. (2008). Simultaneous inference in general parametric models. Biometrical Journal, 50, 346-363.

Jack, K. M., Lenz, B. B., Healan, E., Rudman, S., Schoof, V. A. M., \& Fedigan, L. (2008). The effects of observer presence on the behavior of Cebus capucinus in Costa Rica. American Journal of Primatology, 70, 490-494. 
Jong, W. D. (2001). Tree and forest management in the floodplains of the Peruvian Amazon. Forest Ecology and Management, 150, 125-134.

Kalbitzer, U., \& Chapman, C. A. (2018). Primate responses to changing environments in the Anthropocene. In U. Kalbitzer \& K. Jack (Eds.), Primate life histories, sex roles and adaptability. Developments in primatology: progress and prospects (pp. 283-310). Springer.

Knight, T. (2010) The abundance and diversity of raptors along three riverine transects within the Pacaya-Samiria National Reserve, Peru. (Unpublished thesis) Durrell Institute of Conservation and Ecology, University of Kent Canterbury.

LaBarge, L. R., Hill, R. A., Berman, C. M., Margulis, S. W., \& Allan, A. T. L. (2020). Anthropogenic influences on primate antipredator behavior and implications for research and conservation. American Journal of Primatology, 82, e23087.

Lenth, R. (2019). emmeans: Estimated marginal means, aka least-squares means. R package version 1.3.2. https://CRAN.Rproject.org/package=emmeans. Accessed 23 Oct 2019.

Lüdecke, D. (2019). Collection of convenient function for common statistical computations. R package version 0.17.5. https://github.com/strengehacke/sjstats. Accessed 25 Oct 2019.

Lynch Alfaro, J. W., De Sousa, E., Silva Jr., J., \& Rylands, A. B. (2012). How different are robust and gracile capuchin monkeys? An argument for the use of Sapajus and Cebus. American Journal of Primatology, 74, 273-286.

Lynch Alfaro, J. W., Izar, P., \& Ferreira, R. G. (2014). Capuchin monkey research priorities and urgent issues. American Journal of Primatology, 76, 705-720.

Makin, D. F., Payne, H. F. P., Kerley, G. I. H., \& Shrader, A. M. (2012). Foraging in a 3-D world: how does predation risk affect space use of vervet monkeys? Journal of Mammalogy, 93, 422-428.

Maréchal, L., Semple, S., Majolo, B., Qarro, M., Heistermann, M., \& MacLarnon, A. (2011). Impacts of tourism on anxiety and physiological stress levels in wild male Barbary macaques. Biological Conservation, 144, 2188-2193.

McDougall, P. (2012). Is passive observation of habituated animals truly passive? Journal of Ethology, 30, 219-223.

Mikula, P., Šaffa, G., Nelson, E., \& Tryjanowski, P. (2018). Risk perception of vervet monkeys Chlorocebus pygerythrus to humans in urban and rural environments. Behavioral Processes, 147, 21-27.

Nowak, K., le Roux, A., Richards, S. A., Scheijen, C. P. J., \& Hill, R. A. (2014). Human observers impact habituated samango monkeys' perceived landscape of fear. Behavioral Ecology, 25, 1199-1204.

Nowak, K., Hill, R., Wimberger, K., \& le Roux, A. (2016). Risk-taking in Samango monkeys in relation to humans at two sites in South Africa. In M. T. Waller (Ed.), Ethnoprimithology. Developments in primatology: progress and prospects (pp. 301-314). Springer.

Ordiz, A., Støen, O., Delibes, M., \& Swenson, J. E. (2011). Predators or prey? Spatio-temporal discrimination of human-derived risk by brown bears. Oecologia, 166, 59-67.

Palagi, E., \& Norscia, I. (2011). Scratching around stress: hierarchy and reconciliation make the difference in wild brown lemurs (Eulemur fulvus). Stress, 14, 93-97.

Papworth, S., Milner-Gulland, E. J., \& Slocombe, K. (2013). Hunted woolly monkeys (Lagothrix poeppiggii) show threat-sensitive responses to human presence. PLOS ONE, 8, e62000.

Parsons, A. W., Bland, C., Forrester, T., Baker-Whatton, M. C., Schuttler, S. G., McShea, W. J., Costello, R., \& Kays, R. (2016). The ecological impact of humans and dogs on wildlife in protected areas in eastern North America. Biological Conservation, 203, 75-88.

Pereira, P. H. C., Leal, I. C. S., \& de Araújo, M. E. (2016). Observer presence may alter the behavior of reef fishes associated with coral colonies. Marine Ecology, 37, 760-769.

Pittet, M., \& Bennett, P. (2014). Examining the state of biodiversity using camera traps in the Pacaya Samiria National Reserve, Peru. In P. Meek \& P. Fleming (Eds.), Camera trapping: wildlife management and research (pp. 53-60). CSIRCO Publishing.

Pokorny, J., \& Waal, F. (2009). Face recognition in capuchin monkeys (Cebus apella). Journal of Comparative Psychology, 123, 151-160.

Puertas, P., Bodmer, R., \& Aquino, R. (1995). Diversidad y conservacion de primates en la reserve communal Tamshiyacu-Tahuyo, Loreto, Peru. Folia Amazonica, 7, 113-127.

R Core Team. (2018) R: a language and environment for statistical computing. R Foundation for Statistical Computing. https://www.R-project.org/. Accessed 10 Sept 2019.

Riley, C. M., Du Vall- Lash, A. S., Jayasri, S. L., Koenig, B. L., Klegarth, A. R., \& Gumert, M. D. (2016). How living near humans affects Singapore's urban macaques. In M. T. Waller (Ed.), Ethnoprimatology. Primate conservation in the 21st century (pp. 283-300). Springer. 
Schino, G., Troisi, A., Perretta, G., \& Monaco, V. (1991). Measuring anxiety in nonhuman primates: effect of lorazepam on macaque scratching. Pharmacology Biochemistry and Behavior, 38, 889-891.

Sellers, W. I., \& Crompton, R. H. (2004). Automatic monitoring of primate locomotor behavior using accelerometers. Folia Primatologica, 75, 279-293.

Sheehan, R., Papworth, S. (2019) Human speech reduces pygmy marmoset (Cebuella pygmaea) feeding and resting at a Peruvian tourist site, with louder volumes decreasing visibility. American Journal of Primatology, 81, e22967.

Stankowich, T., \& Blumstein, D. T. (2005). Fear in animals: a meta-analysis and review of risk assessment. Proceedings B The Royal Society of Biology, 272, 2627-2634.

Stevenson, P. R., Quiñones, M. J., \& Ahumada, J. (2000). Influence of fruit availability on ecological overlap among four Neotropical primates at Tinigua National Park, Colombia. Biotropica, 32, 533-544.

Stone, A. I. (2007). Responses of squirrel monkeys to seasonal changes in food availability in an eastern Amazonian forest. American Journal of Primatology, 69, 142-157.

Troisi, A. (2002). Displacement activities as a behavioral measure of stress in nonhuman primates and human subjects. Stress, 5, 47-54.

White, C. A., Feller, M. C., \& Bayley, S. (2003). Predation risk and the functional response of elk-aspen herbivory. Forest ecology and Management, 181, 77-97.

Williamson, E. A., \& Feistner, A. T. C. (2011). Habituating primates: processes, techniques, variables and ethics. In J. M. Setchell \& D. J. Curtis (Eds.), Field and laboratory methods in primatology: $a$ practical guide (pp. 33-50). Cambridge University Press. 